\title{
Effects of a ketogenic diet on strength and power
}

\author{
Sean A McCleary, Matthew H Sharp, Ryan P Lowery, Jeremy E Silva, Jacob T Rauch, Jacob A Ormes, \\ Kevin A Shields, John I Georges, Jacob M Wilson* \\ From The Eleventh International Society of Sports Nutrition (ISSN) Conference and Expo \\ Clearwater Beach, FL, USA. 20-21 June 2014
}

\section{Background}

The effects of a LCKD on endurance performance has been investigated several times, and it has already received a review. For this type of activity, no decrements in performance are observed once the participants are adjusted to the diet. However, LCKD's are yet to be investigated in a resistance training model. One study has examined strength in relation to a LCKD, finding no decrements, yet this study failed to incorporate a well-controlled training protocol.

\section{Methods}

The subjects all participated in the LCKD then all participated in the control diet 3 months later. They were reported as having 30 hours of training per week, although the training is not adequately described. All participants volunteered to participate in this study. Additionally over the course of three months, a significant training adaptation could occur. Thus, the results of this study are inconclusive. Additionally, data is lacking for LCKD's in a healthy population. We aim to investigate the effects of a LCKD compared to a high carbohydrate diet, more typically used by athletes, on measures of athletic performance and perceived effects of exercise to eight weeks of periodized resistance training. Consent to publish the results was obtained from all participants.

\section{Results}

For all strength and power measures there was a time effect. The 1RM bench press increased in both the $\operatorname{LCKD}(10.3 \pm 4.4 \mathrm{~kg})$ and western $(9.5 \pm 4.0 \mathrm{~kg})$. The $1 \mathrm{RM}$ squat increased in both $\operatorname{LCKD}(12.7 \pm 5.9 \mathrm{~kg})$ and western $(15.2 \pm 7.6 \mathrm{~kg})$. The wingate peak power increased in both the $\operatorname{LCKD}(51.8 \pm 64.7 \mathrm{~W})$ and western $(80.5 \pm 66.8 \mathrm{~W})$.

* Correspondence: jmwilson@ut.edu

The University of Tampa, Tampa, Florida, USA

\section{Conclusion}

Both the LCKD and western group experienced an increase in bench press $1 \mathrm{RM}$ strength, squat $1 \mathrm{RM}$ strength, and wingate peak power. In the literature there is a lack of studies testing a LCKD diet on strength and power performance. For purely aerobic performance, there is no difference between high carbohydrate and high fat as long as a 3-4 week period for adaptation to a high fat diet is permitted. However, one study attempted to simulate a race-like environment, which incorporated anaerobic sprints during the aerobic event. This study found that no differences were present during the aerobic portion, but the time to travel $4 \mathrm{~km}$ in the sprint was significantly greater in the ketogenic group. In our study we were able to demonstrate that a LCKD can produce similar strength and power gains to a western diet.

Published: 1 December 2014

doi:10.1186/1550-2783-11-S1-P41

Cite this article as: McCleary et al:: Effects of a ketogenic diet on strength and power. Journal of the International Society of Sports Nutrition 201411 (Suppl 1):P41.

Submit your next manuscript to BioMed Central and take full advantage of:

- Convenient online submission

- Thorough peer review

- No space constraints or color figure charges

- Immediate publication on acceptance

- Inclusion in PubMed, CAS, Scopus and Google Scholar

- Research which is freely available for redistribution 